\title{
O conhecimento popular acerca dos insetos no município de Cariré, Ceará, Brasil
}

\author{
The popular knowledge about insects the municipality of Cariré, in state Ceará, \\ Brazil
}

\author{
Ana Carolina Brasileiro Melo ${ }^{* 1}$, Frede Lima-Araujo ${ }^{2}$, Joaquim Evando Freire ${ }^{3} \mathrm{e}$ \\ Petrônio Emanuel Timbó Braga ${ }^{4}$ \\ 1,2, Graduandos de Ciências biológicas, Universidade Estadual Vale do Acaraú-UVA, Ceará, Brasil \\ ${ }^{3}$ Mestre,Professor , Universidade Estadual Vale do Acaraú-UVA, Ceará, Brasil \\ ${ }^{4}$ Doutor,Professor, Universidade Estadual Vale do Acaraú-UVA, Ceará, Brasil
}

\begin{abstract}
Resumo
Os insetos sempre estiveram relacionados com o homem durante a sua história, seja de forma positiva, seja de forma negativa, sendo gerado conhecimento sobre esse grupo através do contato, da observação ou da oralidade. Este trabalho teve por objetivo verificar o conhecimento etnoentomológico de parte da população do município de Cariré, estado do Ceará, Brasil, de forma a estabelecer uma comparação entre o conhecimento local e o científico. O estudo foi realizado entre os meses de maio e julho de 2013, através da aplicação de entrevistas semiestruturadas a 49 moradores, com idade acima de 18 anos. Quanto aos hábitos alimentares, observou-se, principalmente, o consumo da formiga tanajura (Atta sp.), através do seu abdome, frito ou in natura. A espécie também foi indicada para tratamento de inflamações na garganta. O mel de abelha (Hymenoptera) foi citado, tanto de forma alimentar quanto na utilização para o tratamento de gripe, de tosse e de inflamação da garganta, prática comprovada cientificamente pela literatura. Também foram abordadas questões acerca de atividade lúdicas e místicas que envolvem estes animais, esta última ligada, principalmente, à questão de sorte e de previsões meteorológicas ligadas a mudanças de estação.
\end{abstract}

Palavras-chave: Etnobiologia. Entomologia. Percepções

\begin{abstract}
Insects have always maintained relationship with the man during their history, either in a positive or negative form, being generated knowledge about this group through contact, observation or orality. This study aimed to verify the ethnoentomological knowledge of the population in the city of Cariré, state of Ceará, Brazil, in order to establish a comparison between local and scientific knowledge. The study was conducted between the months May and July of 2013, through the application of interviews semi-structured of 49 residents, aged over 18. Regarding eating habits, is especially observed the consumption of tanajura ant (Atta sp.), through its abdomen, fried or in natura. The species was also indicated for the treatment of sore throats. Honey bees (Hymenoptera) was cited, both feed form, as use for treating flu, coughs and sore throat, practice scientifically proven by literature. Questions about playful and mystical activities involving these animals were also addressed, the last one is mainly linked to the question of luck and weather forecasts related to seasonal changes.
\end{abstract}

Keywords: Ethnobiology. Entomology. Perceptions 


\section{Introdução}

$\mathrm{O}$ $s$ insetos, como são denominados o grupo pertencente à Classe Insecta, abrigam o maior grupo de animais em diversidade no planeta Terra. Já foram descritas, até o momento, aproximadamente, um milhão de espécies no mundo e acredita-se que milhares ainda estão por serem descobertas (LEWINSOHN; PRADO, 2005). Devido à grande diversidade e riqueza de espécies, os insetos sempre mantiveram contato com o homem, seja de forma negativa, por atuarem como pragas agrícolas e urbanas; na transmissão de doença, gerando medo e repulsa (NASSARE, 1997), seja positiva, através da dispersão de sementes, polinização, fonte de alimento e medicamento (COSTA NETO; PACHECO, 2005; COSTA NETO, 2011) ou, até mesmo, atuando no imaginário de forma mística ou religiosa (COSTA NETO, 2007).

A investigação destes conhecimentos populares é de domínio da etnoentomologia, que visa analisar como os insetos são percebidos, classificados, conhecidos e utilizados pelas populações humanas (COSTA NETO, 2003). Na literatura são encontrados exemplos de como o conhecimento etnoentomológico pode ser apropriadamente decodificado e utilizado (COSTA NETO, 2004), no entanto, se comparado a outros estudos etnobiológicos, como a utilização de plantas medicinais, os insetos ainda são pouco estudados (ALVES; DIAS, 2010).

A investigação foi realizada no município de Cariré, Ceará, que possui como fitofisionomia predominante a Caatinga, único bioma exclusivamente brasileiro, ou seja, grande parte do patrimônio biológico dessa região não é encontrada em nenhum outro lugar do mundo além do nordeste do Brasil. Essa posição ímpar entre os biomas do Brasil, entretanto, não foi suficiente para garantir à Caatinga o destaque que merece. Ao contrário, esse bioma tem sido sempre colocada em segundo plano quando se discutem políticas para estudo e conservação da biodiversidade do país (SILVA et al., 2003). No que diz respeito à sua fauna de insetos, a mesma ainda é pobremente conhecida, e são fundamentais levantamentos faunísticos na área da do semiárido nordestino brasileiro para o conhecimento das estruturas taxonômicas e funcionais da biodiversidade (GOMES; MANTILLA, 2011). O conhecimento popular acerca dos insetos auxilia no fortalecimento da compreensão de como estes seres influenciam ou são influenciados pela vida humana. Este trabalho teve por objetivo verificar o conhecimento etnoentomológico de parte da população do município de Cariré, estado do Ceará, de forma a estabelecer uma comparação entre o conhecimento local e o científico, resgatando e valorizando os saberes da diversidade entomológica em diferentes aspectos.

\section{Material e método}

O município de Cariré ( $3^{\circ} 57^{\prime} 02^{\prime \prime} \mathrm{S}$ e $\left.40^{\circ} 28^{\prime} 24^{\prime \prime} \mathrm{W}\right)$, inserido na depressão sertaneja norte-cearense, Brasil, apresenta uma área de $756,89 \mathrm{Km}^{2}$ e uma população de 18.347 moradores (IPECE, 2012). A abordagem ocorreu por meio de entrevistas semiestruturadas, orais, no período de maio a julho de 2013. Ressalta-se que antes da entrevista foram mostradas imagens de insetos, à população, representativas das principais ordens, como Hymenoptera, Isoptera, Mantodea, Orthoptera, Coleoptera, Lepidoptera, Blattaria, entre outros, a fim de fazerlhes recordar os principais grupos desta classe, visto que muitos animais não-insetos podem ser incluídos nesta etnocategoria (COSTA NETO; MAGALHÃES, 2007).

Os aspectos éticos foram resguardados durante toda a investigação, tal como previsto na Resolução 196/96 do Conselho Nacional de Saúde do Brasil (BRASIL, 1996), tendo sido o projeto de pesquisa aprovado pelo Comitê de Ética em Pesquisa da Universidade Estadual Vale do Acaraú (Protocolo n. 991 e Processo n. 411895, CAAE: 00270039000-11). Foram entrevistados aleatoriamente em locais públicos, como praças e mercados, moradores de ambos os sexos, a partir de 18 anos de idade, que possuíam, no ato da entrevista, condições cognitivas para responderem ao questionário, que abordava questões sobre formas de utilização das espécies pertencentes à entomofauna local.

Mediante à disponibilidade e aceitação voluntária para participar do estudo, os entrevistados foram convidados a assinar um termo de consentimento livre e esclarecido (TCLE).

Os dados obtidos foram analisados segundo o modelo de união das diversas competências individuais (MARQUES, 1991), onde toda informação pertinente ao assunto pesquisado deve ser considerada. Posteriormente, os dados foram tabulados e analisados por intermédio de procedimentos da estatística descritiva, através do cálculo das frequências relativas das respostas dadas. Ressalta-se que, referente à soma das frequências, em alguns casos podem ultrapassar o número esperado, pois alguns dos tópicos tiveram mais de uma resposta citada pelo mesmo entrevistado.

\section{Resultados e discussão}

Foram entrevistadas 49 pessoas, das quais, $63,3 \%$ $(n=31)$ pertenciam ao sexo masculino e $36,7 \%(n=18)$ ao feminino. O maior percentual de entrevistados encontrava-se na faixa etária de 18 a 40 anos $(44,9 \%, \mathrm{n}=22)$. As faixas etárias de 41 a 60 anos e os maiores de 60 anos apresentaram percentuais de $34,7 \%$ ( $n=17)$ e $20,4 \%(n=10)$, respectivamente. Com relação ao nível de escolaridade, a maioria detinha apenas o ensino fundamental $(67,4 \%$, $\mathrm{n}=33)$, seja completo $(24,5 \%, \mathrm{n}=12)$, ou incompleto $(42,9 \%$, $\mathrm{n}=21)$, e apenas $6,1 \%(\mathrm{n}=3)$ o ensino superior completo. 


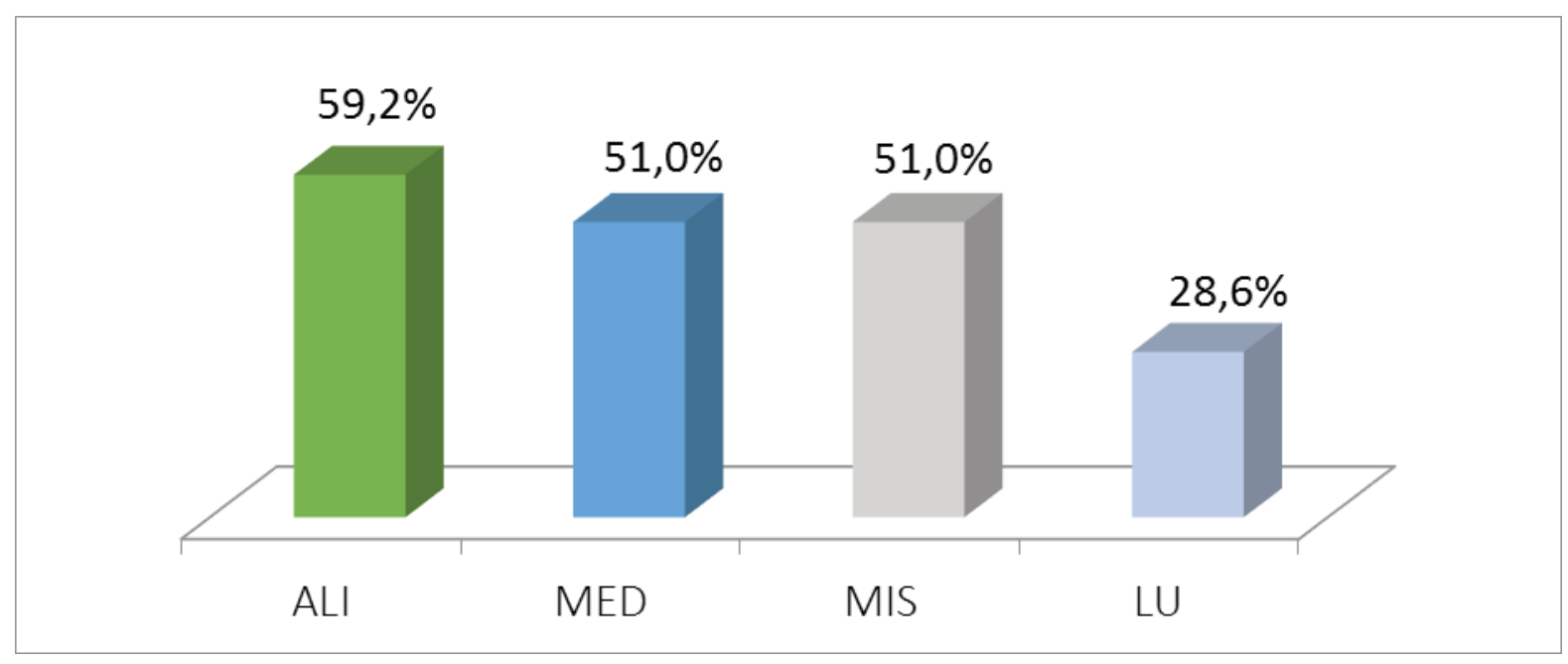

Figura 2- Porcentagem de entrevistados que afirmaram conhecer sobre as formas de utilização de insetos em Cariré, Ceará, 2013, mencionadas nas entrevistas, onde: ALI- alimentar; MED- medicinal; MIS- Atividades Místicas; LU- Atividades lúdicas.

Além de outros níveis de escolaridade $(10,2 \%, \mathrm{n}=5)$, parte dos entrevistados não detinha nenhuma escolaridade $(16,3 \%, n=8)$.

Uma parcela considerável dos participantes afirmou ter conhecimento da utilização de insetos para, pelo menos, um dos fins mencionados na pesquisa, são eles: a utilização alimentar (59,2\%, n=29), medicinal (51,0\%, $\mathrm{n}=25)$, em atividades místicas $(51,0 \%, \mathrm{n}=25)$ e lúdicas $(28,6 \%, n=14)$ (Figura 2).

Desde os tempos antigos, os animais e alguns produtos extraídos a partir deles têm sido utilizados como recursos terapêuticos nos sistemas médicos em muitas culturas ao redor do mundo (ALVES; DIAS, 2010). Mesmo com o grande avanço da medicina alopática a partir da segunda metade do século XX (VEIGA JUNIOR, 2008), o uso de fito e zooterápicos ainda continuam a ser uma importante alternativa no uso medicinal. Para Dominguéz
(2010), a medicina popular é compreendida como um conjunto de crenças e de práticas médicas populares que se enraízam num saber local, constituído pela experiência acumulada e sujeito a contatos culturais com outros sistemas. Conhecimentos e práticas sobre a entomoterapia são transmitidos, principalmente, através da tradição oral, de geração em geração (COSTA NETO, 2005).

Nesse estudo, dentre o conhecimento relativo aos insetos empregados para fins medicinais, a abelha (Hymenoptera: Apidae) foi a mais citada $(44,9 \%, n=22)$, tendo o seu mel indicações para o tratamento de algumas enfermidades, principalmente do trato respiratório (Tabela 1).

Segundo Costa Neto (1998), os meles de abelhas Apis mellifera (Lepeletier, 1836) e de abelhas nativas da subfamília Meliponinae são utilizados como fonte energética, podendo ser considerados como nutracêuticos

Tabela 1 - Insetos mais citados com finalidades medicinais e sua forma de utilização pelos moradores de Cariré, Ceará.

\begin{tabular}{cccccc}
\hline Ordem & $\begin{array}{c}\text { Nome } \\
\text { popular }\end{array}$ & $\begin{array}{c}\text { Parte } \\
\text { utilizada }\end{array}$ & $\begin{array}{c}\text { Forma de } \\
\text { utilização }\end{array}$ & Indicações & $\begin{array}{c}\text { Número } \\
\text { de } \\
\text { citações }\end{array}$ \\
\hline Hymenoptera & $\begin{array}{c}\text { Abelha } \\
\text { africanizada }\end{array}$ & Mel & In natura & $\begin{array}{c}\text { Gripe, tosse, } \\
\text { Inflamação na } \\
\text { garganta }\end{array}$ & 22 \\
\hline Isoptera & Cupim & $\begin{array}{c}\text { Cupim e } \\
\text { cupinzeiro }\end{array}$ & Chá & $\begin{array}{c}\text { Gripe, Inflamação } \\
\text { na garganta, asma }\end{array}$ & 4 \\
\hline Hymenoptera & $\begin{array}{c}\text { Abelha } \\
\text { africanizada }\end{array}$ & Tompleto & Frito & Não souberam \\
dizer
\end{tabular}


e recomendados para o tratamento de diabetes, bronquites, gripe e dores de garganta. Na região amazônica, o mel de abelha Melipona sp. é usado contra dores de garganta (FIGUEIREDO, 1994 apud COSTA NETO; RAMOS-ELOURDY; PINO, 2006), enquanto que na região nordestina, no povoado de Remanso, na Bahia, o mel de M. scutellaris (Latreille, 1811) é indicado para tratamento da tosse (COSTA NETO, 2005).

Na literatura científica é reportado o uso do mel de abelhas para outros fins medicinais, como no controle do crescimento bacteriano de espécies de importância médica, como Salmonella sp., Shigella sp. e Escherichia coli, e no tratamento de determinados problemas de saúde, como gastroenterites, anemia, úlcera gástrica e feridas (JEFFREY; ECHAZARRETA, 1996).

Da abelha, ainda, foi mencionado o uso do seu ferrão $(4,1 \%, n=2)$, indicado para o tratamento do Mal de Parkinson (Tabela 1). Em estudos sobre a apitoxina, Leite e Rocha (2005) observaram que o veneno de abelha contém dopamina, um neurotransmissor que aumenta a atividade motora, deficiente nos pacientes com Parkinson, agindo como um estimulante para estas funções.

O cupim foi citado com fim terapêutico a partir do uso de um chá $(8,2 \%, n=4)$, preparado através do cozimento dos insetos junto com o cupinzeiro, indicado para gripe, inflamação na garganta e asma (Tabela 1). No estado da Bahia, o mesmo é indicado para doenças na garganta, assim como o abdômen de tanajura (Atta sp.) (COSTA NETO, 2011). Costa Neto, Ramos-Elorduy e Pino (2006) citam Lages Filho (1934), ao se referirem à utilização de cupins em água fervente no estado de Alagoas, e Brancch e Silva (1983), sobre o uso de um chá feito em Alter do Chão, estado do Pará, com adultos de Microcerotermes exiguus (Hagen, 1858), usado contra a asma.

Ainda para fins medicinais, foi citado o consumo de baratas fritas $(8,2 \%, n=4)$. Os entrevistados, entretanto, não souberam informar a sua aplicação médica, assim como também afirmaram não fazer o uso desta prática (Tabela 1). Este conhecimento, segundo eles, deve-se à observação da mídia televisiva, do uso em outras culturas. Na Nigéria, a barata (Periplaneta americana) é utilizada para curar feridas frescas e dores de ouvido (BANJO et al., 2004 apud COSTA NETO; RAMOS-ELOURDY; PINO, 2006).

Dos entrevistados que expressaram o uso alimentar dos insetos, a formiga tanajura (Atta sp.) teve o maior número de citações $(42,9 \%, \mathrm{n}=21)$. Os moradores de Cariré afirmaram fazer uso, principalmente, do seu abdômen, frito ou in natura (Tabela 2).

Como fonte de alimento, há registros do consumo de insetos na maioria dos estados brasileiros, sendo estes ingeridos em estado imaturo (ninfas, larvas e pupas) e adulto, parcialmente ou inteiros, assim como os produtos elaborados por eles, como o mel, o propólis, o pólen e a cera (COSTA NETO; RAMOS-ELOURDY; PINO, 2006). Quanto ao seu valor nutricional, os insetos contêm quantidades consideráveis de proteínas, se levada em consideração, por exemplo, a concentração desta macromolécula nas carnes de frango e boi, além de serem ricos em vitaminas e sais minerais (COSTA NETO; 2003).

Costa Neto, Ramos-Elorduy e Pino (2006) afirmaram que, dos insetos comestíveis, as formigas são as preferidas em regiões tropicais, especialmente fêmeas de formigas cortadeiras do gênero Atta. Além de ser consumida como alimento, a saúva é ingerida pelos seus valores terapêuticos em Cariré (Tabela 1).

As larvas pertencentes, provavelmente, às famílias Bruchidae e Curculionidae, presentes no coco da palmeira Babaçu (Attalea speciosa Mart. ex Spreng), também foram mencionadas como fonte de alimento. Segundo os entrevistados, possui gosto semelhante ao do coco. Defoliart (2002) cita que tipos diferentes de besouros têm sido reportados como alimento no Brasil, embora não se informem a identificação a nível de espécie. Coimbra Jr. (1984) também constatou, no Parque Indígena Aripuanã, no estado de Rondônia, o uso alimentar a partir de larvas desses animais.

Outro representante de coleópteros, o chupão ou gorgulho (Curculionidae), foi mencionado como inseto comumente encontrado no feijão armazenado do sertanejo, podendo estes serem, posteriormente, cozidos juntos.

Caso peculiar foi a citação da utilização da barata (Periplaneta americana), do grilo e do gafanhoto para fins

Tabela 2 - Parte e forma de utilização de insetos citados como fonte de alimento pelos moradores de Cariré, Ceará.

\begin{tabular}{llllc}
\hline Ordem & Nome popular & $\begin{array}{c}\text { Parte } \\
\text { utilizada }\end{array}$ & $\begin{array}{c}\text { Forma de } \\
\text { utilização }\end{array}$ & $\begin{array}{c}\text { Número } \\
\text { citações }\end{array}$ \\
\hline Hymenoptera & Formiga tanajura & Abdômen & Frito ou in natura & 21 \\
\hline Coleoptera & Larva do babaçu & Completo & Frito ou in natura & 4 \\
\hline Blattaria & Barata & Completo & Frito & 3 \\
\hline Orthoptera & Gafanhoto & Completo & Frito & 2 \\
\hline Hymenoptera & Abelha & Mel & In natura & 2 \\
\hline Coleoptera & Chupão ou & Completo & Cozido no feijão & 1 \\
\hline Orthoptera & Gorgulho & & & 1 \\
\hline
\end{tabular}


Tabela 3 - Principais citações de insetos mencionados em atividades lúdicas no município de Cariré, Ceará

\begin{tabular}{cccc}
\hline Ordem & $\begin{array}{c}\text { Nome } \\
\text { popular }\end{array}$ & Atividade & Número de citações \\
\hline Blattaria & Barata & Música & 4 \\
\hline Orthoptera & Grilo & Brincadeira & 4 \\
\hline Lepidoptera & Lagarta & Brincadeira & 3 \\
\hline Lepidoptera & Borboleta & Música & 3 \\
\hline
\end{tabular}

alimentícios (Tabela 2). Os entrevistados, entretanto, afirmaram não fazer o uso destes animais e atribuíram estas observações à mídia televisiva. Segundo Martins (2009), a televisão tem se consolidado como principal fonte de entretenimento e informação para a maioria da população e ocupa papel de fundamental importância na formação da identidade nacional. Informações, antes restritas a uma menor parcela da população, foram "massificadas" através deste meio de comunicação.

Apesar de menos reportado que outras categorias, a presença de brincadeiras envolvendo os insetos também teve menção (Tabela 3). A menção do grilo em atividades lúdicas foi lembrada pelos entrevistados na "Brincadeira do grilo", onde forma-se uma fila e uma pessoa à parte pergunta: "cadê o grilo?", o primeiro da fila responde: "está lá atrás", correndo para trás da fila. A lagarta foi citada na popular brincadeira infantil de "lagarta pintada", onde forma-se uma roda e, com as mãos abertas, uma criança puxa nas costas da mão da outra, cantando: "lagarta pintada quem foi que pintou, foi o velho mais a velha que aqui passou." A barata foi recordada através da música popular: "a barata diz que tem sete saias de filó, é mentira da barata ela tem é uma só...", e a borboleta em "borboletinha, tá na cozinha, fazendo chocolate para a madrinha, Poti Poti, perna de pau, olho de vidro e nariz de pica-pau, pau pau".

Segundo Pinto e Tavares (2010), as atividades lúdicas possibilitam a incorporação de valores, o desenvolvimento cultural, a assimilação de novos conhecimentos, o desenvolvimento da sociabilidade e da criatividade. Michahelles (2011) considera que as "cantigas e brincadeiras-de-roda", a partir das suas características musicais, poéticas, lúdicas e da sua singularidade enquanto manifestação folclórica, está relacionada ao processo musicoterápico, que, segundo Oliveira et al. (2012), é utilizada, desde a antiguidade, de diversas maneiras como medida preventiva, paliativa e, até mesmo, como terapêutica, como é o caso da depressão e de alguns distúrbios neurodegenerativos.

Quanto às crenças, sabe-se que os insetos têm desempenhado papéis místicos e mágicos em uma variedade de culturas (COSTA NETO, 2005). Nesse estudo, uma parcela considerável da população $(51,0 \%, \mathrm{n}=25)$ afirmou conhecer ao menos uma crença sobre insetos (Tabela 4), relacionando alguns destes à sorte, como a esperança, a abelha, a borboleta e o louva-a-deus.

A afirmação de boa sorte transmitida pelo louva-deus se dá, provavelmente, pela sua própria morfologia. Como indica Costa Lima (1938): “são os mantídeos, devido a atitude característica que tomam quando pousados, e que lembra a de uma pessoa ajoelhada em oração, conhecidos pelo nome de louva-deus". Já a borboleta é símbolo da alma em muitas culturas, como a tradição Celta e Grega. Em outras, é vista como de metamorfose e renascimento (GRIMASSI, 2004).

Ao gafanhoto e à cigarra foram atribuídas previsões meteorológicas acerca das estações do ano (Tabela 4). A região semiárida brasileira apresenta apenas duas estações bem definidas, os períodos seco e chuvoso. Como a taxa de evapotranspiração na Caatinga geralmente excede à de precipitação durante a maior parte do ano, muitas comunidades passam por problemas com o abastecimento de água potável, o que desperta uma maior curiosidade quanto a possíveis mudanças no tempo.

A abelha como portadora de boa sorte, observada neste trabalho, também foi mencionada em um estudo

Tabela 4 - Crenças relacionadas aos insetos no município de Cariré, Ceará

\begin{tabular}{lll}
\hline Ordem & Nome popular & Superstição ou crenças citadas \\
\hline \multirow{2}{*}{ Orthoptera } & Esperança & "Quando pousa na gente dá sorte." \\
\cline { 2 - 3 } & Gafanhoto & "Canta pra chegar o inverno." \\
\hline Hemiptera & Cigarra & "Canta quando vai fazer verão." \\
\hline \multirow{2}{*}{ Hymenoptera } & Cavalo-do-cão & "Dá azar." \\
\cline { 2 - 3 } & Abelha & "Dá sorte." \\
\cline { 2 - 3 } & Vespa & "Sinal de chuva." \\
\hline Lepidoptera & Borboleta & "Dá sorte." \\
\hline Mantodea & Louva-a-Deus (Bota-mesa) & "Quando se vê coisa boa vai acontecer." \\
\hline
\end{tabular}


Tabela 5 - Categoria das respostas quanto à importância dos insetos no município de Cariré, Ceará

\begin{tabular}{lc}
\hline Categorias & Citações \\
\hline Todos os seres vivos são importantes. & 15 \\
\hline $\begin{array}{l}\text { Fazem parte da cadeia alimentar e/ou equilíbrio } \\
\text { ambiental. }\end{array}$ & 9 \\
\hline Produção de mel. & 5 \\
\hline Proteção e/ou purificação da natureza. & 3 \\
\hline Criação divina. & 1 \\
\hline Não sabe. & 1 \\
\hline
\end{tabular}

na região amazônica. A cera de abelha Melipona sp., além de indicada para tratar dores de ouvido, é recomendada contra o mau-olhado (FIGUEIREDO, 1994 apud COSTA NETO; RAMOS-ELOURDY; PINO, 2006).

O cavalo-do-cão (Pompilidae) foi visto como portador de azar por alguns entrevistados, assim como na pesquisa de Araújo (2013) acerca da percepção de graduandos da Universidade Federal do Rio Grande do Norte sobre estes animais.

Durante a pesquisa, os entrevistados também foram questionados sobre a importância dos insetos ao meio ambiente, cujas respostas foram agrupadas em diferentes categorias (Tabela 5).

As afirmativas quanto aos benefícios dos insetos ao meio ambiente foram expressivas, visto que, historicamente, eles são tidos como objeto de repulsa e medo, como citado por um dos entrevistados: "quando vejo um, trato logo de matar". Os insetos, entretanto, são de crucial importância para o equilíbrio ambiental, atuando como decompositores, herbívoros, polinizadores, dispersores, predadores e fonte alimentar (GOMES; MANTILLA, 2011). Algumas das respostas foram voltadas ao valor econômico que estes animais propiciam, como a produção de mel pelas abelhas $(10,2 \%, n=5)$. Para Khan, Matos e Lima (2009), o desenvolvimento da apicultura no Ceará tem sido uma importante fonte de renda alternativa à agricultura familiar, e a localização do estado é bastante propícia ao seu bom desempenho.

\section{Conclusões}

Os insetos participam de forma relativa na vida sociocultural dos moradores entrevistados no município de Cariré, se levarmos em consideração a porcentagem de respostas afirmativas dadas por estes, apresentandose a sua utilização nas diversas maneiras explanadas na entrevista, tais como alimentar, medicinal, em atividades lúdicas e místicas.

O conhecimento de diferentes formas de utilização medicinal dá espaço a novas investigações científicas acerca das propriedades terapêuticas destes animais e do uso alimentar de novas espécies conhecidas para o Ceará.

O fato de uma expressiva parcela de entrevistados terem reportado a importância dos insetos no meio ambiente nos faz supor que, apesar de ainda serem vistos com repugnância e sem utilidade para algumas pessoas, os participantes demonstraram sensibilidade quanto aos benefícios que estes seres propiciam, o que pode, consecutivamente, atuar na manutenção da entomofauna local.

\section{Agradecimentos}

Ao órgão de financiamento FUNCAP (Fundação Cearense de Apoio ao Desenvolvimento Científico e Tecnológico) pelo apoio prestado ao projeto e a todos os voluntários que auxiliaram nesta pesquisa com suas entrevistas.

\section{Referências}

ALVES, R. R. N.; DIAS, T. L. P. Usos de invertebrados na medicina popular no Brasil e suas implicações para conservação. Tropical Conservation Science, v. 3, p. 159-174, 2010.

ARAÚJO, C. M. M. O conhecimento Etnoentomológico do Cavalo-do-cão (Hymenoptera, Pompilidae) pelos graduandos da Universidade Federal do Rio Grande do Norte. In: XI Congresso de Ecologia do Brasil. Porto Seguro, Bahia. 2013.

BRASIL. Ministério da Saúde. Conselho Nacional de Saúde. Resolução n.196, de 10 de outubro de 1996. Dispõe sobre diretrizes e normas reguladoras de pesquisa envolvendo os seres humanos. Brasília: Diário Oficial da União. 16 Out. 1996.

COIMBRA JR, C. E. A. Estudos de ecologia humana entre os Suruí do Parque Indígena Aripuanã, Rondônia. 1. O uso de larvas de coleópteros (Bruchidae e Chuculionidae) na alimentação. Revista Brasileira de Zoologia, São Paulo, v. 2, n. 2, p. 35- 47, 1984.

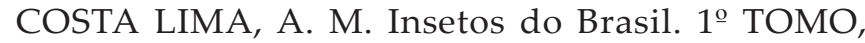
cap. XV, Ordem Mantodea. 1938. Escola Nacional de Agroecologia, Disponível em: <http://www. 
acervodigital.ufrrj.br/insetos/insetos.htm>. Acesso em: 19 dez. 2013.

COSTA NETO, E. M. Folk taxonomy and cultural significance of "abeia" (Insecta, Hymenoptera) to the Pankararé, Northeastern Bahia State, Brazil. Journal of Ethnobiology, v. 18, n. 1, p. 1-13, 1998.

COSTA NETO, E. M. Insetos como fonte de alimento para o homem: valoração de recursos considerados repugnantes. Interciência, v. 3, n. 28, , p. 136-140, 2003.

COSTA NETO, E. M. Estudos etnoentomológicos no estado da Bahia, Brasil: uma homenagem aos 50 anos do campo de pesquisa. Biotemas, v. 17, n. 1, p. 117-149, 2004.

COSTA NETO, E. M. Entomotherapy, or the medicinal use of insects. Journal of Ethnobiology, v. 25, n. 1, p. 93-114, 2005.

COSTA NETO, E. M. Fulgora Laternaria LINNAEUS. 1758 (Hemiptera: Fulgoridae) na concepção dos moradores do povoado de Pedra Branca, Santa Terezinha, Bahia, Brasil. Revista de Ciências Ambientais, v. 1, n. 1, p. 35-37, 2007.

COSTA NETO, E. M. A zooterapia popular no Estado da Bahia: registro de novas espécies animais utilizadas como recursos medicinais. Ciência \& Saúde Coletiva, v. 16, p. 1639-1650, 2011.

COSTA NETO, E.; MAGALHÃES, H. F. The ethnocategory "insect" in the conception of the inhabitants of Tapera County, São Gonçalo dos Campos, Bahia, Brazil. Anais da Academia Brasileira de Ciências, v. 79, n. 2, p. 239-249, 2007.

COSTA NETO, E. M.; PACHECO, J. M. Utilização medicinal de insetos no povoado de Pedra Branca, Santa Terezinha, Bahia, Brasil. Biotemas, v. 18, n. 1, p. 113-133, 2005.

COSTA NETO, E. M.; RAMOS-ELORDUY, J.; PINO, J. M. Los insectos medicinales de Brasil: primeros resultados. Boletín Sociedad Entomológica Aragonesa, v. 38, n. 1, p. 395-414, 2006.

DEFOLIART, G. R. The human of insects as a food resource: A bibliographic progress. 2002. Disponível em: <http://www.food-insects.com/book7_31/ Chapter\%2006\%20\%20South\%20America\%20Brazil. html>. Acesso em: 11 dez. 2013.

DOMINGUÉZ, M. F. Recurso à Medicina Popular. Etnicex, n. 1, p. 61-78, 2010.
GOMES, P. P.; MANTILLA, G. M. Entomofauna de diferentes estratos verticais em floresta de Caatinga. $X$ Congresso de Ecologia do Brasil. São Lourenço MG, 2011.

GRIMASSI, R. Enciclopédia de Wicca e bruxaria. Editora Gaia: São Paulo, 2004.

IPECE - Instituto de Pesquisa e Estratégia Econômica do Ceará. Perfil Básico Municipal 2012 - Cariré. Fortaleza, 2012. Disponível em: <http://www.ipece.ce.gov.br/ publicacoes/perfil_basico/pbm-2012/Carire.pdf $>$. Acesso em: 09 nov. 2013.

JEFFREY, A. E.; ECHAZARRETA, C. M. Medical uses of honey. Revista Biomédica, v. 7, n. 1, p. 43-49, 1996.

KHAN, A. S.; MATOS, V. D.; LIMA, P.V. P. S. Desempenho da apicultura no estado do Ceará: competitividade, nível tecnológico e fatores condicionantes. RESR, São Paulo. n. 3, v. 47, p. 651-675, 2009.

LEITE, G. L. D; ROCHA, S. L. Apitoxina. Unimonte Científica, Montes Claros, v. 7, n. 1, 2005.

LEWINSOHN, T. M.; PRADO, P. I. Quantas espécies há no Brasil? Megadiveridade, v. 1, n. 1, p. 36-42, 2005.

MARQUES, J. G. W. Aspectos ecológicos na etnoictiologia dos pescadores do Complexo Estuarino-lagunar Mundaú-Manguaba. Tese de Doutorado. Universidade Estadual de Campinas. 1991. 292p.

MARTINS, S. T. A construção da notícia sobre a influência da TV e do telejornalismo no Brasil. XIV Congresso de Ciências da Comunicação na Região Sudeste. Rio de Janeiro. maio, 2009. Disponível em: <http:// www.intercom.org.br/papers/regionais/sudeste2009/ resumos/R14-0528-1.pdf>. Acesso em: 03 jan. 2014.

MICHAHELLES, B. Cantigas e Brincadeira-de-roda na Musicoterapia. 2011. Disponível em: <http://www. taturana.com/mono.html>. Acesso em: 21 nov. 2013.

NASSARE, A. Q. Artrópodos y psicopatologia: aproximación a dos entidades clínicas. Bol. S. E. A, n. 20, p. 217-218, 1997.

OLIVEIRA, G. C.; LOPES, V. R. S.; DAMASCENO, M. J. C.; SILVA, E. M. A contribuição da musicoterapia na saúde do idoso. Cadernos UniFOA. 2012. Disponível em: <http://unifoa.edu.br/cadernos/edicao/20/85-94. pdf>. Acesso em: 09 jan. 2014.

PINTO, C. L.; TAVARES H. M. O lúdico na aprendizagem: apreender e aprender. Revista da Católica, v. 2, n. 3, p. 226-235, 2010. 
SILVA, J. M. C.; TABARELLI, M.; FONSECA, M. T. da; LINS, L. V. Biodiversidade da caatinga: áreas e ações prioritárias para a conservação. Brasília, DF: Ministério do Meio Ambiente: Universidade Federal de Pernambuco, 382 p, 2003.

VEIGA JUNIOR, V. F. Estudo do consumo de plantas medicinais na Região Centro-Norte do Estado do Rio de Janeiro: aceitação pelos profissionais de saúde e modo de uso pela população. Revista Brasileira de Farmacognosia, v. 2, n. 18, p. 308-313, 2008. 